REVIEW ARTICLE

\title{
Cancer Treatment Based on the Selective Accumulation of a Photosensitiser and Laser Light Irradiation: A Review
}

\author{
Zahra AL-Timimi \\ Laser Physics-College of Science for Women, Babylon University, Iraq
}

\begin{abstract}
Background: Cancer Photodynamic Therapy (CPDT) is a promising future treatment quality based on the selective accumulation of a photosensitiser in the malignant tissues and the dependent irradiation with laser light.

Objective: The aim of this work was to estimate an optimum effect involves the performance of a photosensitizing agent served by irradiation at a wavelength corresponding to an absorbance band of the sensitizer. In the appearance of oxygen, a series of effects lead to direct tumour cell death and damage to the microvasculature and initiation of a local inflammatory reaction.

Methods: Photosensitiser is a material that sensitizes an organism, cell, or tissue to the light. It is a deeprooted part of CPDT, which absorbed by cancerous cells and exposed to laser light, gets activated, damaging and killing cancer cells. The direct targeting of laser source on hyper proliferative tissue and its preferential origin absorption at the targeted site gives rise CPDT double selectivity with least damage to adjacent normal tissues.

Results: Photosensitiser absorbs the light and then produces an active form of oxygen, which destroys nearby cancer cells. The photosensitiser is able to spoil the blood vessels in the tumour, that way preventing cancer from receiving any necessary nutrients. The light which needed to activate most of the photosensitisers cannot pass through more than about one-third of an inch of tissue, because of that reason, the CPDT is usually used to treat cancer on or just under the skin or on the lining of internal organs. In addition, CPDT may activate the immune system to attack the tumour cells, directly killing cancer cells.
\end{abstract}

Conclusion: This review focuses on the aspects of CPDT as an advanced and original site directed therapy for cancer treatment and the other non-oncogenic diseases. Minimal average of tissue toxicity controlled a long-term morbidity, deficiency of intrinsic or acquired resistance mechanisms.

Keywords: Photodynamic therapy, Photodiagnostics, Photosensitiser, Laser irradiation

\section{Introduction}

Cancer photodynamic therapy (CPDT) is a treatment combines a drug purported a photosensitisers or photosensitising agent with a specific category of irradiation (laser irradiation or light emitting diodes (LEDs)) to kill cancer cells. ${ }^{1}$

Radiation therapy is one of the primary modalities of cancer treatment; the major challenge of radiation therapy is maximising the radiation dose delivered to malignant tissues while minimising damage to the surrounding normal tissues. ${ }^{2}$

The ever-growing hope of clinicians to treat and achieve cancer patients with CPDT is actually restricted due to the available. The requirement of more productive interdisciplinary research efforts

*Correspondence: AL-Timimi Zahra, Laser Physics-College of Science for

Women, Babylon University, Ira, email: dr. altimimizahra@gmail.com ORCID: 0000-0002-3209-553X between cell biologists, physical, and medical sciences that are concentrate on discovery of more selective and typical photosensitizers, preferably understanding of the mechanism of CPDT, optical properties of various tumorous tissues and targeted path to make CPDT more selective for the further clinical applications in many non-oncologic diseases. ${ }^{3,4}$

Furthermore, CPDT can be repeated without compromising its effectiveness. These are significant defining factors for chemotherapeutics or radiotherapeutics. ${ }^{5,6}$

The cell destruction is the consequence of the photochemical irritation of the photosensitizers that produce reactive oxygen species (ROS) particularly in the reduction of oxygen by the electron transfer system of mitochondria that has a damaging influence on cell organelles and molecules required for normal cell functioning. The normal cells remain unaffected due to sub cellular localization of 
photosensitisers selectively in tumour cells. ${ }^{7,8}$

Apoptosis, necrosis and autophagy are a biological mechanism which have all been identified as Programmed Cell Death (PCD) mechanisms during $\mathrm{PDT}^{9,10}$. The most preferred and common mechanism is the apoptosis (figure 1).

Multicellular organisms use it in order to remove the cells that are not needed by the body. The difference between apoptosis and necrosis is that the apoptosis is ordinarily lasts a lifetime and be profitable for the body, whereas the necrosis is cell death caused by the cellular damage acutely.,11

Apoptosis has characteristic morphological advantage like plasma membrane blebbing, cell shrinkage, chromatin condensation and deoxyribonucleic acid fragmentation, and commences with the enzymes of the caspase proteases form a complex series of Cysteine protease activation of multi unit called. , $^{52}$

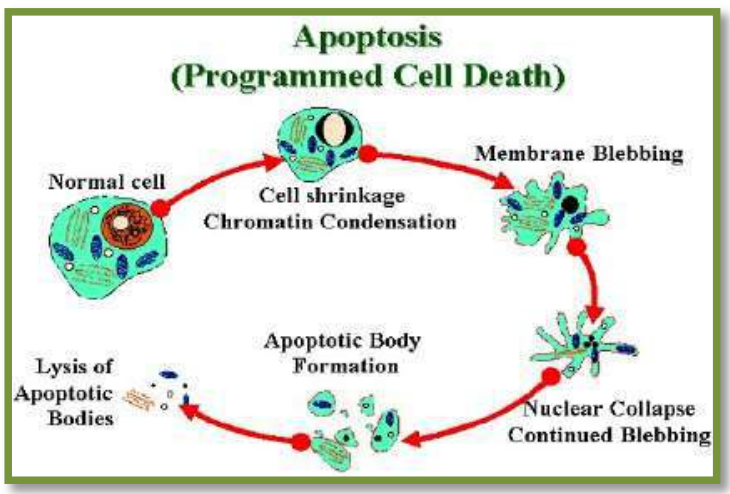

Figure 1: Biological mechanism of apoptosis programmed cell death. ${ }^{13}$

Through direct targeting of irradiation source on hyper proliferative tissue and its discriminatory absorption at the targeted site gives PDT its double selectivity with minimal damage to the adjacent normal tissues. ${ }^{14,15} \mathrm{CPDT}$ can be used to treat some cancers or in precancerous conditions when the tumour, is on or near to the lining of internal organs like cancers that affect the oesophagus, head and neck, lung, mouth and skin (but not melanoma). ${ }^{14,16}$

The biological damage happen as a result of the optical irritation of a photosensitizer in the existence of oxygen which is generally indicated to as "Photodynamic Action". ${ }^{17}$ ROS have short halflife ( $<1$ picoseconds) which is responsible for localized nature of the effectiveness; and the unassuming energy need.

\section{Fluorescence of photosensitisers}

Most of the photosensitizers have a fluorescence emission from the ground state singlet state. The photosensitizer molecule absorbs the light that excites it to singlet state which, is able to lose energy by fluorescence or undergo intersystem crossing to long lived photosensitizer triplet state that; able to carry out the photochemistry and lose its energy by phosphorescence (figure 2).

Most of the photosensitisers preferentially accumulate in the neoplastic tissues, and their fluorescence characteristic may be advantageous in the detection and diagnosis of lesions. For clinically used photosensitisers with a wavelength range from (420-780 nm) (figure 3).

The greater length of light waves penetrates tissue deeper such as a blue light attenuates greatly within (1-2 $\mathrm{mm})$ whereas a red light may penetrate more than $(5 \mathrm{~mm})$. In addition, the shorter wavelength is more possibly to be absorbed by melanin and haemoglobin.

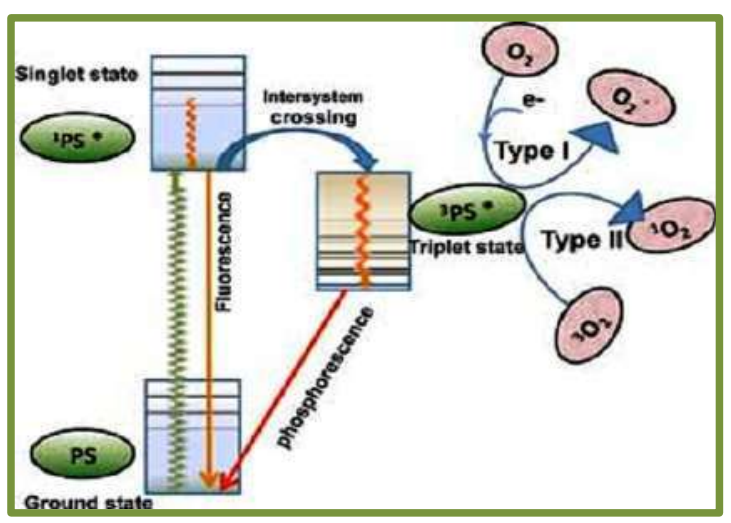

Figure 2: Pathway of the photochemical mechanisms in photodynamic therapy. ${ }^{18}$

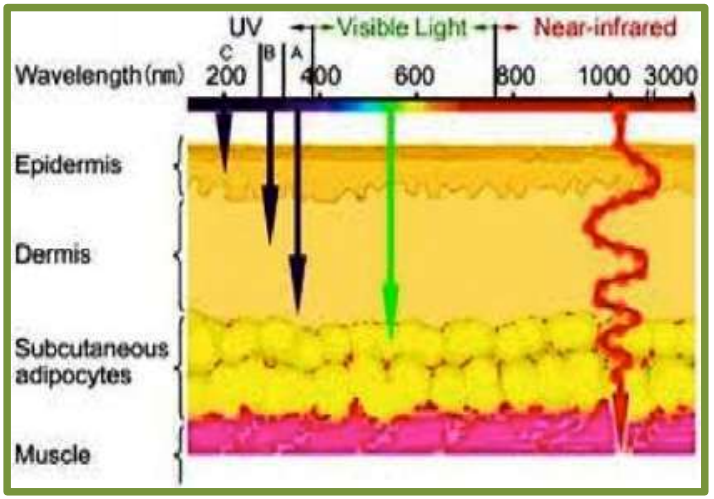

Figure 3: Light waves penetrate into human tissue, infraredlight penetrate deeply ${ }^{19}$

\section{Application of photosensitisers in cancer therapy}

Utmost of the photosensitisers applied in cancer therapy is based on a tetrapyrrole structure which similar to the protoporphyrin included in the 
hemoglobin. ${ }^{20} \mathrm{~A}$ typical photosensitising agent should be a single pure compound to provide quality control analysis with a low manufacturing cost and high-grade stability in storage. ${ }^{21}$

It should have a great absorption peak within $600 \mathrm{~nm}-800 \mathrm{~nm}$ because of the absorption of photons with wavelengths higher than $800 \mathrm{~nm}$ does not produce enough energy to stimulate the oxygen to its singlet state so as the ability for creating a substantial yield of reactive oxygen species simultaneous irradiation. ${ }^{15,16}$

Considering the penetration of light within the tissue increases with its wavelength, the agents with a strong absorbance in the intense red essentially like chlorins, bacteriochlorins, and phthalocyanines advance improvement in tumor control. It should have no obscure toxicity and approximately rapid clearance from the normal tissues, whereby minimizing phototoxic side impressions. ${ }^{22}$

\section{Application of photosensitisers in brain tumours}

infrequent reports recommend that a definite inflammatory response and necrotic cell death after an illumination is very important in the immune stimulating function of CPDT, while others propose that photosensitisers that provide further apoptosis and less inflammation are proper for medical applications such as brain tumors where swelling is undesirable. ${ }^{23}$

Modern findings record that a certain CPDT induced apoptotic cell death mechanisms are profoundly immunogenic as well as proficient of driving antitumor immunity. Lastly, the light mediated destruction of the Photosensitizers recognized as photobleaching was earlier thought to be unacceptable, but some statements suggest that this field may make light dosimetry less important and over treatment is avoided when the Photosensitisers is destroyed through the illumination. ${ }^{24}$

This study discovers the future treatment of Cancer-based on the selective accumulation of a photosensitiser in the malignant tissues and the dependent irradiation with laser light that can be beneficial for cancerous cells and exposed to laser light gets activated, damaging and killing cancer cells. ${ }^{25}$

This study will help the researcher to uncover the critical areas of photodynamic therapy (PDT) that many researchers were not able to explore. Thus, a new theory on the aspects of cancer photodynamic therapy (CPDT) as an advanced and original site directed therapy for cancer treatment and the other non-oncogenic diseases may be arrived at.

\section{Conclusion}

CPDT is still considered a unique and promising antitumour strategy. The advantages of CPDT corresponded with the surgery, chemotherapy or radiotherapy are modified the long-term morbidity.

Moreover, the fact that CPDT does not compromise scheduled treatment choices for the residual or recurrent disease because of a lack of natural mechanisms of ${ }^{1} \mathrm{O}_{2}$ elimination and unique mechanism of cytotoxicity mutations which; confer resistance to radiotherapy or chemotherapy does not compromise anti-tumour efficacy.

Finally, there are many conventional anti-tumour treatments carry a risk of inducing immune suppression. This short review focuses on the aspects of CPDT as an advanced and original site directed therapy for cancer treatment and the other non-oncogenic diseases.

Conflict of interest: The author declares no conflict of interest

Funding: No funding

Submitted: $18^{\text {th }}$ August 2020

Final revision received: $4^{\text {th }}$ November 2020

Accepted: $25^{\text {th }}$ November 2020

Published: $1^{\text {st }}$ December, 2020

\section{References}

1. Eber AE, Perper $M$, Verne SH, Magno $\mathrm{R}$, ALOmair IAO, ALHarbi M, et al. Photodynamic therapy. In: Lasers in dermatology and medicine: dermatologic applications. 2018. p261-73. DOI: 10.1007/978-3-319-76118-3_16

2. AL-Timimi Z, Mustafa F. Recognizing the effectiveness of the diode laser $850 \mathrm{~nm}$ on stimulate the proliferation and viability of mice mesenchymal stem cells derived from bone marrow and adipose tissue. Iraqi J Vet Sci . 2019: 32: 285-90.

DOI: 10.33899/ijvs.2019.153869

3. Dąbrowski JM, Arnaut LG. Photodynamic therapy (PDT) of cancer: from local to systemic treatment. Photochem Photobiol Sci. 2015;14:1765-80.

DOI: $10.1039 / \mathrm{c} 5 \mathrm{pp} 00132 \mathrm{c}$

4. Zahra AT. Technological Advancements to Reduce the Influence of Absorption and Scattering on the Optical Imaging. Bangladesh Med Res Counc Bull. 2020;46:64-5.

DOI: $10.3329 /$ bmrcb.v46i1.47472

5. Al Habashneh R, Asa'ad FA, Khader Y. Photodynamic therapy in periodontal and periimplant diseases. Quintessence Int . 2015;46:677-90. DOI: 10.3290/j.qi.a34078

6. Al-Timimi Z. Evaluation of the Significance of Constant Laser Therapy, $532 \mathrm{~nm}$, in Various 
Exposure Times on the Healing Process of Wounds Infected by Acinetobacter baumannii. The International Journal of Lower Extremity Wounds.:1534734620984039.

DOI: $10.1177 / 1534734620984039$

7. Allison RR, Moghissi K. Photodynamic therapy (PDT): PDT mechanisms. Clin Endosc. 2013;46:24-29.

DOI: $10.5946 /$ ce.2013.46.1.24

8. Al-Timimi Z. Evaluation of the Significance of Constant Laser Therapy, $532 \mathrm{~nm}$, in Various Exposure Times on the Healing Process of Wounds Infected by Acinetobacter baumannii. The International Journal of Lower Extremity Wounds.:1534734620984039.

DOI: $10.1177 / 1534734620984039$

9. Zahara AT. Letter to the editor clinical evaluation of scalpel Er: YAG laser $2940 \mathrm{~nm}$ and conventional surgery incisions wound after oral soft tissue biopsy. Bangladesh Med Res Counc Bull. 2017;43:149.

DOI: $10.3329 /$ bmrcb.v43i3.36429

10. Dhaneshwar S, Patil K, Bulbule M, Kinjawadekar V, Joshi D, Joshi V. Photodynamic therapy for cancer. International Journal of Pharmaceutical Sciences Review and Research. 2014; 27; 125-41. URL:www.globalresearchonline.net/journalcont ents/v27-2/20.pdf

11. Madsen SJ. Physics of Photodynamic Therapy. In: Biomedical Optics in Otorhinolaryngology [Internet]. New York, NY: Springer New York; 2016; 287-309.

DOI: $10.1007 / 978-1-4939-1758-7 \_18$

12. Bu L, Ma X, Tu Y, Shen B, Cheng Z. Optical Image-Guided Cancer Therapy. Curr Pharm Biotechnol. 2013;14:723-32.

DOI : $10.2174 / 1389201014666131226112507$

13. Szymanek M, Chodorowska G, Pietrzak A, Krasowsk D. Apoptosis of T Lymphocytes in Systemic Sclerosis. In: Systemic Sclerosis - An Update on the Aberrant Immune System and Clinical Features. 2012; 69-92

DOI: $10.5772 / 28493$

14. Liang C-P, Nakajima T, Watanabe R, Sato K, Choyke PL, Chen Y, et al. Real-time monitoring of hemodynamic changes in tumor vessels during photoimmunotherapy using optical coherence tomography. J Biomed Opt. 2014;19:098004. DOI: $10.1117 / 1 . J B O .19 .9 .098004$

15. Diam WA, Zahra AT. Characterization and fabrication of Nd:YVO4 disc laser system. In AIP Conference Proceedings 2019; 2123; 020009 DOI: $10.1063 / 1.5116936$
16. Houssein HA, Jaafar MS, Ali Z, Timimi ZA, Mustafa FH. Study of hematocrit in relation with age and gender using low power helium-Neon laser irradiation. In5th Kuala Lumpur International Conference on Biomedical Engineering. Springer, Berlin, Heidelberg. 2011;463-66

DOI: 10.1007/978-3-642-21729-6_117

17. Mustafa FH, Jaafar MS, Ismail AH, Omar AF,Houssein HA, Timimi ZA. Influence of hair color on photodynamic dose activation in PDT for scalp diseases. In5th Kuala Lumpur International Conference on Biomedical Engineering. Springer, Berlin, Heidelberg. 2011; 315-19 DOI: 10.1007/978-3-642-21729-6_82

18. Abrahamse $\mathrm{H}$, Sosthene Mfouo Tynga I. Photodynamic Therapy, a Potential Therapy for Improve Cancer Management. In: Breast Cancer and Surgery. 2018; 181-98

DOI: 10.5772/intechopen.74697

19. Tanaka Y, Tsunemi Y, Kawashima M, Nishida H. The Impact of Near-infrared in Plastic Surgery. Plast Surg An Int J. 2013;1-13. DOI: $10.5171 / 2013.973073$

20. Zahra'a AT. Assessment of the impacts of $830 \mathrm{~nm}$ Low Power Laser on Triiodothyronine (T3), Thyroxine (T4) and the Thyroid Stimulating Hormone (TSH) in the Rabbits. J Med Sci Clin Res. 2014;2:2902-10.

21. Coluzzi DJ, Al Timimi Z, Saleem M. Digitization and Dental Lasers 5. Digitization in Dentistry: ClinicalApplications. 2021;15:141-67.

DOI: 10.1007/978-3-030-65169-5_5

22. Barakat DA, Al-Abbas G, Al-Timimi ZJMA. Utilization of diode laser therapy with wavelength 904nm during pregnancy: A preliminary study. Iraqi Laser Sci J. 2019;1:15-20.

URL: www.iasj.net/iasj/article/178983.

23. Zahra AT. Investigating the effects of green laserirradiation on red blood cells: green laser blood therapy. Int J Appl Res Stud. 2014;3:1-5. Available From: www.researchgate.net/

24. Al Timimi Z, Jaafar MS, Jafri MZ.Comparisonbetween low level laser therapy and exercise for treatment of chronic low back pain. Indian J Physiother Occup Ther-An Int J. 2010;4:102-4.

URL:www.ijpot.com/scripts/IJPOT\%20Julysept $\% 202010$.pdf\#page $=106$

25. Zahra JM. Investigation of the semiconductor laser beam propagation through air and pure water (stable and turbulence). Laser. 2019;1:7-14. URL:www.iasj.net/iasj/download/f16b039079f5 $5 \mathrm{a} 48$ 